\title{
Adaptive Depression in Synaptic Transmission in the Nucleus of the Solitary Tract after In Vivo Chronic Intermittent Hypoxia: Evidence for Homeostatic Plasticity
}

\author{
David D. Kline, ${ }^{1,2,3,4}$ Angelina Ramirez-Navarro, ${ }^{1,2}$ and Diana L. Kunze ${ }^{1,2}$ \\ ${ }^{1}$ Department of Neurosciences, Case Western Reserve University, Cleveland, Ohio 44106, ${ }^{2}$ Rammelkamp Center for Education and Research, MetroHealth \\ Medical System, Cleveland, Ohio 44109, and ${ }^{3}$ Department of Biomedical Sciences and ${ }^{4}$ Dalton Cardiovascular Research Center, University of Missouri- \\ Columbia, Columbia, Missouri 65211
}

The respiratory system is highly pliable in its adaptation to low-oxygen (hypoxic) environments. After chronic intermittent hypoxia $(\mathrm{CIH})$, alterations in the regulation of cardiorespiratory system become persistent because of changes in the peripheral chemoreceptor reflex. We present evidence for the induction of a novel form of homeostatic plasticity in this reflex pathway in the nucleus tractus solitarius (NTS), the site of termination of the chemosensory afferent fibers. CIH induces an increase in NTS postsynaptic cell activity initiated by spontaneous presynaptic transmitter release that is counterbalanced by a reduction in evoked synaptic transmission between sensory afferents and NTS second-order cells. This is accomplished via presynaptic mechanisms involving changes in neurotransmitter release and calcium/calmodulin-dependent kinase II activation.

Key words: hypoxia; synaptic plasticity; presynaptic; CaMKII; respiration; NTS

\section{Introduction}

Adaptation of respiration to changes in arterial oxygen levels has long been recognized as an important means to maintaining respiratory homeostasis. The best known adaptation is that to high altitude in which ventilation increases in a time-dependent manner. This plasticity can manifest in several components of the system, especially the carotid body chemoreflex pathway. Prolonged exposure to low-oxygen (hypoxia) levels increase the sensitivity of chemoafferent activity to a given arterial oxygen level (Powell et al., 2000). Not only do the sensory afferents show plasticity but neural activity and circuits in the nucleus tractus solitarius (NTS), which integrate the chemosensory afferent information, also exhibit a high degree of plasticity (Schmitt et al., 1994; Dwinell and Powell, 1999; Poon and Siniaia, 2000).

A form of respiratory plasticity that has recently received considerable attention is long-term facilitation (LTF) of respiratory motor output. LTF is stimulus specific in that it is only observed after intermittent hypoxia ( $\mathrm{IH}$ ) or episodic carotid sinus nerve stimulation (Prabhakar and Kline, 2002; McGuire et al., 2003). LTF may be one mechanism used to keep the airway open in obstructive sleep apnea syndrome (OSAS) in which an individual's upper airway partially or completely collapses during the

Received Dec. 21, 2005; revised March 22, 2007; accepted March 23, 2007.

This work was supported by National Institutes of Health Grant HL-25830 (D.L.K.). D.D.K. was a Parker B. Francis Fellow in Pulmonary Research while this work was performed. We thank Dr. David Friel and Dr. Ben Strowbridge for their helpful comments in the preparation of this manuscript and Dr. Nanduri R. Prabhakar for the generous use of his hypoxia chamber during the first half of this study.

Correspondence should be addressed to Dr. David D. Kline, Dalton Cardiovascular Research Center, University of Missouri-Columbia, 134 Research Park Drive, Columbia, M0 65211. E-mail: klinedd@missouri.edu.

DOI:10.1523/JNEUROSCI.4946-06.2007

Copyright $\odot 2007$ Society for Neuroscience $\quad$ 0270-6474/07/274663-11\$15.00/0 transition from wakefulness to sleep. Chronic IH (CIH) exposure is used as an animal model for OSAS. Both OSAS patients and the $\mathrm{CIH}$ animal models exhibit increases in chemosensory reflexes (Prabhakar and Kline, 2002; McGuire et al., 2003). Evidence suggests that the cardiorespiratory alterations during $\mathrm{CIH}$ originate from the peripheral chemoreceptor reflex (Fletcher, 2001; Peng et al., 2003).

Because of the importance of the NTS in chemosensory processing (Andresen and Kunze, 1994) and the high degree of plasticity this nucleus and its afferent innervation exhibit, we hypothesized that NTS neuronal activity would be significantly altered and play a vital role in chemosensory processing in the $\mathrm{CIH}$ model of OSAS. An increase in the gain of the central component of chemoreceptor processing on respiration after CIH lends credence to this notion (Ling et al., 2001). Thus, a major goal of the study was to identify a potential locus for the central mechanism of facilitation of chemoreceptor discharge that develops in $\mathrm{CIH}$. We present evidence that an increase in postsynaptic cell activity, driven by an augmentation in afferent input and enhancement in spontaneous synaptic discharge, is counterbalanced by a reduction in evoked synaptic transmission between sensory afferents and NTS second-order cells after CIH in the adult rat. The latter is accomplished via presynaptic mechanisms involving changes in neurotransmitter release and calcium/calmodulin-dependent kinase II (CaMKII) activation. These results illustrate that a novel form of homeostatic plasticity occurs in the autonomic nervous system during $\mathrm{CIH}$.

\section{Materials and Methods}

All experiments were performed on adolescent Sprague Dawley rats of either sex exposed to either room air or CIH. Hypoxic exposure began 
between 3 and 4 weeks of age, and brainstem slices were generated after hypoxia. The Institutional Animal Care and Use Committee of Case Western Reserve University and University of Missouri-Columbia approved all experiments and protocols.

\section{Exposure to $\mathrm{CIH}$}

Exposure to intermittent hypoxic consisted of rats inspiring alternating cycles of 21 and $6 \%$ oxygen, nine episodes per hour, $8 \mathrm{~h} / \mathrm{d}$. This was accomplished by placing standard rat cages containing unrestrained animals in either an in-house-made chamber (Peng et al., 2003) or a commercially available hypoxic system (BioSpherix, Redfield, NY) for exposure to intermittent hypoxia. The animals were fed ad libitum. In either system, the chamber was flushed with alternating cycles of pure nitrogen and compressed air (or pure oxygen) to reach the desired inspired oxygen levels. To achieve hypoxic levels, pure nitrogen was flushed in the chamber ( $2 \mathrm{~min}$ ). Oxygen levels decreased from 20.9 to $7 \% \mathrm{O}_{2}$ within $80 \mathrm{~s}$ and remained between 6.5 and $6.2 \%$ for $50 \mathrm{~s}$ before returning to normoxic (NORM) conditions. Chamber $\mathrm{O}_{2}$ levels increased to $20.9 \%$ within 2 min and remained at this level for 3 additional minutes before the ensuing hypoxic exposure. The duration of the gas flow during each hypoxic and normoxic episode was regulated by solenoid valves controlled by either a timer or computer. Ambient oxygen, carbon dioxide, temperature, and humidity levels were continuously monitored. Animals were subjected to intermittent hypoxia between 9:00 A.M. and 5:00 P.M. for 3, 10, or 30 consecutive days. Between 5:00 P.M. and 9:00 A.M., animals were exposed to room air. Control animals consisted of rats not exposed to $\mathrm{CIH}$. Animals were housed in standard rat cages placed in the vivarium, in the hypoxic chamber but only exposed to $21 \% \mathrm{O}_{2}$, or alternatively, on the top surface of the hypoxic chamber during littermate $\mathrm{CIH}$ exposure. All brain slice experiments or tissue harvesting were performed the morning after $\mathrm{CIH}$ exposure or the comparable normoxic time period.

\section{Brainstem slice preparation and electrophysiology}

Brainstem slices containing the NTS were prepared from 5- to 10-weekold rats (Kline et al., 2002). The age of the rat depended on the duration of the hypoxia exposure. Animals were anesthetized with ether and decapitated. The brainstem was removed and placed in ice-cold artificial CSF (ACSF) containing the following (in $\mathrm{mM}$ ): $125 \mathrm{NaCl}, 3 \mathrm{KCl}, 1.2$ $\mathrm{KH}_{2} \mathrm{PO}_{4}, 1.2 \mathrm{MgSO}_{4}, 25 \mathrm{NaHCO}_{3}, 10 \mathrm{D}$-glucose, and $2 \mathrm{CaCl}_{2}$, saturated with $95 \% \mathrm{O}_{2}-5 \% \mathrm{CO}_{2}$, pH $7.4(300 \mathrm{mOsm})$. Horizontal slices $(300 \mu \mathrm{m})$ were cut with a sapphire knife (Delaware Diamond Knives, Wilmington, DE) using a vibrating microtome (VT 1000S; Leica, Nussloch, Germany). Tissue sections were placed in a superfusion chamber that contained inlet and outlet ports for ACSF flow. The submerged sections were secured with a nylon mesh and superfused at a flow rate of 3-4 $\mathrm{ml} / \mathrm{min}$ with ACSF at $31-33^{\circ} \mathrm{C}$. All recordings were made from cells in the caudal NTS (medial and commissural subnuclei) that receives a high density of carotid body afferent fiber termination and cardiorespiratory innervation (Andresen and Kunze, 1994; Kline et al., 2002).

Caudal NTS neurons were visualized using an Olympus Optical (Tokyo, Japan) BX-51WI microscope (40× magnification) equipped with fluorescence, differential interface contrast, and an infrared-sensitive camera. The pipette was guided using a piezoelectric micromanipulator (PCS-5000; Burleigh, Victor, NY). Recording electrodes (7151 and 8250 glass, 3.5-5.0 M $\Omega$ ) were filled with a solution containing the following (in mM): $10 \mathrm{NaCl}, 130 \mathrm{~K}^{+}$gluconate, $11 \mathrm{EGTA}, 1 \mathrm{CaCl}_{2}, 10 \mathrm{HEPES}, 1$ $\mathrm{MgCl}_{2}, 2 \mathrm{MgATP}$, and 0.2 NaGTP, pH 7.3 (295-300 mOsm). In experiments in which we recorded miniature EPSCs (mEPSCs), the recording electrodes contained the following (in $\mathrm{mM}$ ): $5 \mathrm{NaCl}, 130 \mathrm{Cs}^{+}$methanesulfonate, $10 \mathrm{CsCl}, 11 \mathrm{EGTA}, 1 \mathrm{CaCl}_{2}, 10 \mathrm{HEPES}, 1 \mathrm{MgCl}_{2}, 2 \mathrm{MgATP}, 0.2$ NaGTP, and 5 QX-314 [N-(2,6-dimethylphenylcarbamoylmethyl) triethylammonium], $\mathrm{pH}$ 7.3; the extracellular solution contained $1.0 \mu \mathrm{M}$ tetrodotoxin (TTX) and $10 \mu \mathrm{m}$ bicuculline. Data was recorded using an Axopatch 200B or Multiclamp700B amplifier, filtered at $2 \mathrm{kHz}$, and sampled at $10 \mathrm{kHz}$ using pClamp 8 and 10 software (Molecular Devices, Palo Alto, CA). Recordings were made in whole-cell voltage- and currentclamp modes. Neurons were rejected if resting membrane was more positive than $-45 \mathrm{mV}$ under current-clamp mode during initial mem- brane rupture. In all voltage-clamp protocols, neurons were clamped at $-60 \mathrm{mV}$. No leak subtractions, liquid junction potential corrections, or series resistance compensations were performed. Input resistance was monitored throughout recordings.

\section{Electrophysiological protocols}

Solitary tract-evoked EPSC recording. EPSCs were generated by placing a concentric bipolar stimulating electrode (Frederick Haer Company, Bowdoinham, ME) on the solitary tract (TS) containing chemosensory and other visceral afferents (Andresen and Kunze, 1994) and stimulating at a duration of $0.1 \mathrm{~ms}$ with an isolated programmable stimulator (A.M.P.I., Jerusalem, Israel). Although stimulation of the TS in this manner globally activates all sensory fibers, we limited our recordings to caudal NTS neurons. The intensity of TS stimulation was progressively increased until an EPSC was evoked. Additional increasing intensity did not alter EPSC amplitude. Final stimulation intensity was set at $1.5 \times$ threshold. Recordings were made in voltage-clamp mode while TS was excited between 0.5 and $50 \mathrm{~Hz}$.

Loose cell recordings. Single-unit extracellular recordings in NTS slices were made by using the loose cell-attached method. This method permits the recording of individual cell activity without disturbing cell integrity or intracellular milieu. Briefly, the same pipettes used for whole-cell recordings were used to form a "loose" seal (50-200 M $\Omega$ ) of caudal NTS cells. Pipettes for such recordings were filled with a solution containing the following (in mM): $150 \mathrm{NaCl}, 10$ HEPES, 11 glucose, $2 \mathrm{CaCl}_{2}, 1.2$ $\mathrm{MgCl}_{2}, 3 \mathrm{KCl}, \mathrm{pH}$ 7.4. Extracellular activity was recorded in currentclamp $(I=0)$ mode only from neurons responding to TS stimulation.

$m E P S C$ recordings. Miniature currents were recorded in caudal NTS neurons in the presence of TTX 5 min after initiation of whole-cell access in voltage-clamp mode. Data were acquired continuously for $120 \mathrm{~s}$. The lack of action potential (AP) generation to current ramps at the end of the protocol verified that miniature events were not attributable to actionpotential-driven spontaneous network activity. Detection threshold for analysis was set at twice the RMS noise level, and events were manually confirmed.

Asynchronous EPSC injection. To examine postsynaptic response to asynchronous EPSCs (aEPSCs), cells from NORM and CIH slices were held at $-60 \mathrm{mV}$ in current-clamp mode in the presence of 2,3dihydroxy-6-nitro-7-sulfonyl-benzo[f]quinoxaline (NBQX) (10 $\mu \mathrm{M})$ and bicuculline $(10 \mu \mathrm{M})$. Asynchronous activity for injection was chosen based on an average current observed in $\mathrm{CIH}$ slices (see Fig. 6). Five individual current sweeps of $2 \mathrm{~s}$ were injected while membrane potential was examined. The amplitude of injection was one to two times the current recorded.

\section{Data analysis}

Data were analyzed via Molecular Devices Clampfit, Synaptosoft (Decatur, GA) Mini-Analysis Program, and Origin (Microcal, Northampton, MA) software. Each data point for a given trial was an average of 10-20 sweeps for evoked activity. Statistical analysis was performed with Microsoft (Seattle, WA) Excel and SigmaStat 3.1 (Systat Software, Port Richmond, CA). Jitter (SD of EPSC latency) was analyzed as described previously (Doyle and Andresen, 2001; Kline et al., 2002). In brief, the differential current trace was generated using Clampfit software. The time of EPSC initiation from stimulus artifact was determined as the first data point that exceeds noise. Because data were recorded at $10 \mathrm{kHz}$, the first data point, in $100 \mu$ s intervals, was used for jitter analysis. Synaptic events were compared between normoxic and hypoxic rats using unpaired $t$ test. Data were presented as mean \pm SEM. Miniature EPSC averages, frequency, and distributions were analyzed using MiniAnalysis Program and compared using unpaired $t$ test and KolmogorovSmirnov tests.

All drugs were purchased from Tocris Bioscience (Ellisville, MO) and Sigma (St. Louis, MO).

\section{Western blot analysis}

After $10 \mathrm{~d} \mathrm{CIH}$, rats were deeply anesthetized with ether and decapitated, and the NTS and nodose-petrosal sensory ganglion (SG) containing presynaptic chemosensory afferent somas were rapidly removed. NTS slices were generated as described for electrophysiological recordings and then 


\section{A NORM}

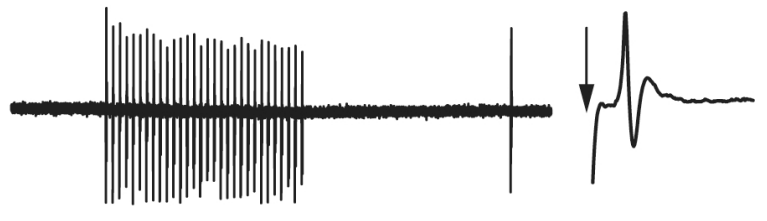

B $\mathrm{ClH}$

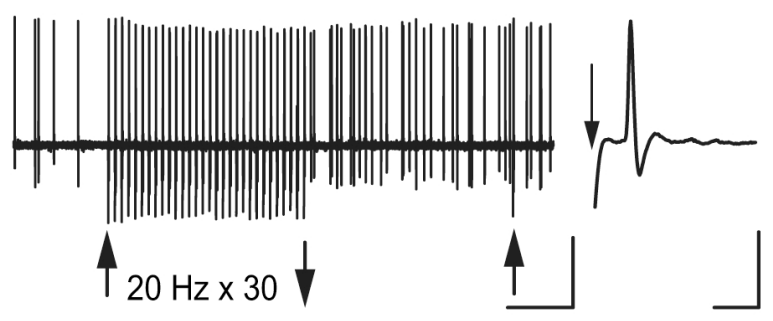

C

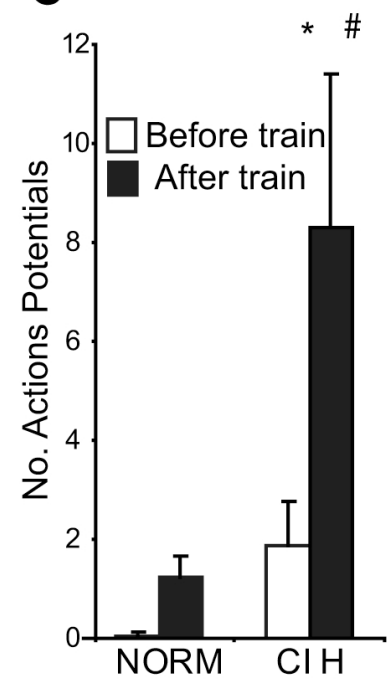

Figure 1. Ten days of $\mathrm{CIH}$ increases NTS action potential discharge. Example of action potential discharge during and after a stimulus train in a NORM $(\boldsymbol{A})$ and $\mathrm{CIH}(\boldsymbol{B})$ NTS slice. The TS was stimulated at $20 \mathrm{~Hz}$ between the arrows and once $1.5 \mathrm{~s}$ after the train at the arrow. Shown is an overlay of two traces. Calibration: $1 \mathrm{mV}, 500 \mathrm{~ms}$. Stimulus artifact is downward defection, and voltage response is upward deflection. Expanded trace of the first action potential in the stimulus train is shown on the right for both groups. Downward arrows illustrate the location of the truncated stimulus artifact. Calibration: $1 \mathrm{mV}, 5 \mathrm{~ms}$. Note that action potential discharge is significantly greater in $\mathrm{ClH}$ after repetitive stimulation compared with NORM. C, Absolute number of action potentials before (open bar) and after (filled bars) the $20 \mathrm{~Hz}$ train in NORM and ClH cells. ${ }^{*} p<0.05$, before vs after evoked discharge; ${ }^{\#}<<0.05$, ClH vs NORM.

trimmed free of the rostral portions of the nucleus and non-NTS tissue. Tissue was pooled from six to eight animals and frozen at $-80^{\circ} \mathrm{C}$ until blotting. The experiment was repeated in three separate groups of animals and tissue.

Frozen adult SG and NTS tissue were resuspended in 5 vol of homogenization buffer consisting of $0.3 \mathrm{~m}$ sucrose, $10 \mathrm{~mm} \mathrm{NaPO}_{4}, \mathrm{pH} 7.2$, and freshly added protease inhibitor cocktail (Roche, Indianapolis, IN) and phosphatase inhibitor cocktail (Calbiochem, La Jolla, CA). After the removal of insoluble protein by centrifugation at $1000 \times g$, the supernatant was centrifuged at 50,000 $\times g$ for 1 h. Supernatant (i.e., cytosol) was collected, and the pellet (i.e., crude membrane fraction) was resuspended in a small amount of SDS buffer, kept on ice for $30 \mathrm{~min}$, and centrifuged for $10 \mathrm{~min}$ at $20,000 \times g$. Protein concentration of the samples, cytosol and crude membrane, was measured by the BCA method (Pierce, Rockford, IL). Equal amounts of cytosol protein were separated on 7.5\% polyacrylamide SDS gels and transferred to polyvinylidene difluoride (PVDF) membranes. PVDF membranes were blocked with 5\% nonfat dry milk in PBS/0.1\% Tween 20 (Fisher Scientific, Pittsburgh, PA) overnight at $4^{\circ} \mathrm{C}$ and incubated with primary antibodies $\alpha$-CaMKII (monoclonal, 1:1500; Upstate Biotechnology, Lake Placid, NY), monoclonal Thr-286 phospho-CaMKII (1:1000; Upstate Biotechnology), or actin (anti-goat, 1:4000; Santa Cruz Biotechnology, Santa Cruz, CA). Actin levels were used to monitor loading of lanes, which were comparable between NORM and CIH samples. After washing, the blots were incubated for $1 \mathrm{~h}$ at room temperature with anti-mouse or anti-goat HRPlinked secondary antibodies in blocking buffer. After wash, the blots were developed using the ECL-PLUS kit (GE Healthcare, Little Chalfont, Buckinghamshire, UK), and the images were captured on HyperfilmECL. Densitometry analysis was performed using Storm PhosphorImager and ImageQuant software (GE Healthcare).

\section{Results}

\section{$\mathrm{CIH}$ increases action potential activity}

$\mathrm{CIH}$ increases carotid body chemoreceptor activity and hypoxic ventilatory responses. Because the NTS is the central termination site of chemosensory axons and is vital in the respiratory reflex to hypoxia (Housley and Sinclair, 1988; Andresen and Kunze,
1994), we hypothesized that $\mathrm{CIH}$ would augment NTS activity not only as a direct result of the increase in chemoreceptor afferent activity but also through changes in synaptic transmission. This could occur as an activity-dependent response or via a direct effect of hypoxia at the synapse. Extracellular single-cell recordings were made from NTS neurons using the loose cellattached patch-clamp technique in brainstem slices. Ten-day-old $\mathrm{CIH}$ rats were compared with rats exposed only to room air (normoxic or NORM) before, during, and after a physiological stimulus train. Representative examples are shown in Figure $1, A$ and $B$. Interestingly, a greater proportion of $\mathrm{CIH}$ cells exhibited spontaneous action potentials compared with NORM in the $500 \mathrm{~ms}$ before the stimulus train ( 0.56 vs $0.11 ; n=9 ; p<0.05, z$ test). This coincided with more APs in neurons from $\mathrm{CIH}$ slices $(1.9 \pm 0.9$ vs $0.1 \pm 0.06$ APs; $p=0.07$ ) (Fig. 1C). Repetitively stimulating the TS at a rate similar to hypoxic sensory neuron discharge in vivo (30 episodes at $20 \mathrm{~Hz}$ ) (Vidruk et al., 2001) produced a train of action potentials in NORM (Fig. $1 A$ ) and CIH (Fig. $1 B$ ) slices. Average action potential frequency in NORM cells during the $1.5 \mathrm{~s}$ period after the train was $4.3 \pm 0.7$ $\mathrm{Hz}$ in three of nine cells, excluding the majority of cells (six of nine) that remained quiescent (overall discharge, $1.4 \pm 0.75 \mathrm{~Hz}$; $n=9$ ). In neurons recorded from CIH slices, action potential frequency was $10.6 \pm 2.1 \mathrm{~Hz}$ during the $1.5 \mathrm{~s}$ after the evoked train in seven of nine cells, excluding the two cells not exhibiting changes in activity (overall discharge, $8.3 \pm 2.6 \mathrm{~Hz} ; n=9$ ). The absolute number of APs in the $1.5 \mathrm{~s}$ after an individual train was significantly greater in $\mathrm{CIH}$ than NORM cells $(8.3 \pm 3.1$ vs $1.2 \pm$ $0.2, p<0.05$ ) (Fig. 1C). The proportion of cells exhibiting enhanced action potential discharge was greater in $\mathrm{CIH}$ than NORM rats ( 0.77 vs $0.33 ; p=0.055, z$ test). This result suggested that presynaptic and/or postsynaptic changes occurred at this synapse between the afferent fibers and its second-order neuron in the NTS after CIH.

\section{CIH depresses TS-evoked EPSCs}

Whole-cell voltage-clamp recordings were used to determine whether enhanced synaptic transmission accounts for the increase in extracellularly recorded activity after $\mathrm{CIH}$. The horizontal brainstem-NTS slice preparation permits recording from an NTS neuron activated by a single afferent axon (Bailey et al., 2006), evoking glutamatergic EPSCs in an all-or-none manner by TS stimulation. Exposing rats to $10 \mathrm{~d} \mathrm{CIH}$ induced alterations in EPSC amplitude compared with NORM (Fig. 2A). EPSC amplitude in NORM animals averaged $182.6 \pm 13.9 \mathrm{pA}(n=78$ cells, 49 rats; mean \pm SEM). Current amplitudes ranged from 49.7 to $544.2 \mathrm{pA}$. Unexpectedly, $10 \mathrm{~d}$ CIH significantly depressed EPSC amplitude to $115.9 \pm 10.4 \mathrm{pA}$ ( $n=62$ cells, 37 rats; $p<0.05$ vs NORM, $t$ test). EPSCs ranged from 24.6 to $381.0 \mathrm{pA}$. Jitter between NORM and CIH cells were comparable (NORM, $0.149 \pm$ $0.012 \mathrm{~ms}$ vs $\mathrm{CIH}, 0.153 \pm 0.013 \mathrm{~ms} ; p>0.05)$. Plotting the cumulative fraction of EPSC amplitudes in NORM and $10 \mathrm{~d} \mathrm{CIH}$ 


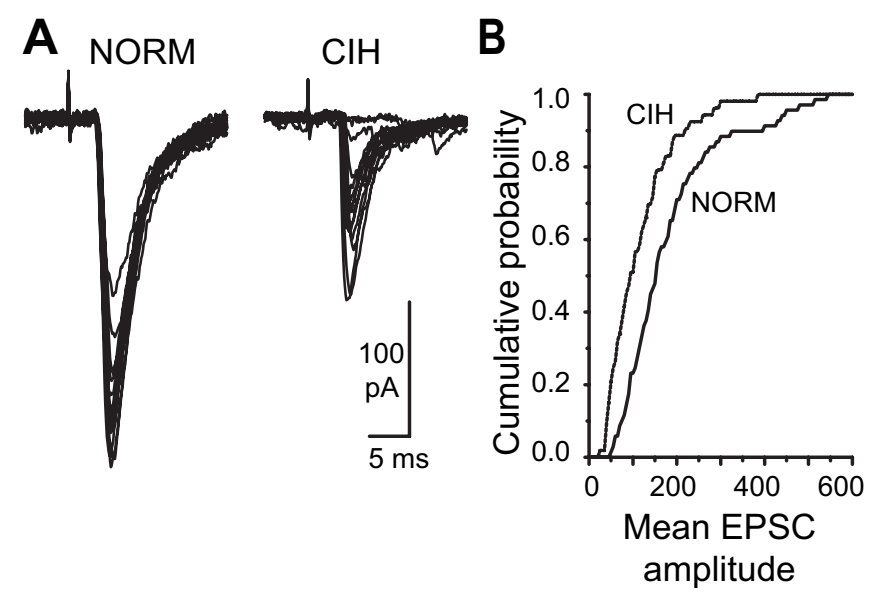

Figure 2. Ten days of $\mathrm{ClH}$ induces EPSC depression. $\boldsymbol{A}$, Representative tracings of EPSCs from a NORM (left) and $10 \mathrm{~d}$ CIH (right) rat brainstem slice. NTS cells were voltage clamped at -60 $\mathrm{mV}$, and the TS was stimulated at $0.5 \mathrm{~Hz}$. Eighteen current traces are shown for both groups. Note the smaller amplitude and greater variability in EPSCs after $\mathrm{CIH}$. B, Plotting the cumulative probability of NORM and CIH TS-evoked EPSC amplitudes illustrates a leftward shift to smaller currents after hypoxia.

animals demonstrated a leftward shift in the curve in $\mathrm{CIH}$ animals (Fig. 2 B).

In four cells exhibiting significantly reduced EPSCs after $10 \mathrm{~d}$ $\mathrm{CIH}$, current amplitudes were analyzed over $15 \mathrm{~min}$ to resolve whether washout of inhibitory intracellular components would reverse the depression and return EPSC amplitude to NORM levels. EPSCs averaged 39.2 \pm 0.9 pA 3 min after whole-cell membrane rupture (taken as time 0). Continuous ACSF superfusion did not alter currents ( $5 \mathrm{~min}, 40.0 \pm 2.7 \mathrm{pA} ; 10 \mathrm{~min}, 40.4 \pm 2.6$ $\mathrm{pA} ; 15 \mathrm{~min}, 37.2 \pm 0.9 \mathrm{pA} ; p>0.05$, paired $t$ test).

In another group of animals, the time course of EPSC alterations during $\mathrm{CIH}$ was evaluated. Three days of $\mathrm{CIH}$ resulted in EPSCs that were comparable with NORM animals and averaged $192.8 \pm 22.0 \mathrm{pA}(n=15$ cells, 9 rats; $p>0.05, t$ test $)$. Three day currents varied from 52.4 to $368.0 \mathrm{pA}$. After $30 \mathrm{~d}$ CIH, EPSCs remained depressed ( $n=6$ cells, 4 rats; $86.5 \pm 6 \mathrm{pA}$ ) and comparable with $10 \mathrm{~d}$ CIH slices.

Because changes in EPSC amplitude occur within $10 \mathrm{~d} \mathrm{CIH}$, the remainder of the study focuses on the potential mechanisms after this period of treatment.

\section{CIH EPSCs are mediated by AMPA receptors}

TS-evoked EPSCs in the NTS are primarily AMPA receptormediated currents blocked by CNQX or NBQX (Andresen and Yang, 1990; Kline et al., 2002). In 10 d CIH slices, we determined the efficacy of AMPA receptor blockade on EPSC amplitude. Under control conditions, CIH currents averaged 71.9 $\pm 16.6 \mathrm{pA}$ $(n=5)$. Bath applying CNQX (10 $\mu \mathrm{M}, 2 \mathrm{~min})$ significantly attenuated EPSCs to $7.8 \pm 2.5 \mathrm{pA}$ ( $p<0.05$, paired $t$ test). The remaining current could not be eliminated by application of the NMDA antagonist AP-5 (50 $\mu \mathrm{M}, 2 \mathrm{~min})$. Currents in the presence of CNQX and AP-5 were $7.4 \pm 2.6 \mathrm{pA}$ ( $p>0.05$, paired $t$ test vs CNQX alone). Washout of both drugs returned currents to baseline conditions ( $87 \pm 33.1 \mathrm{pA} ; p>0.05$ vs baseline). TTX ( $1 \mu \mathrm{M}$; $n=2$ ) completely eliminated the TS-evoked EPSCs. These results confirm that we are examining AMPA receptor-mediated currents in $10 \mathrm{~d}$ CIH slices.

\section{Depression of EPSCs in CIH is mediated by a} presynaptic mechanism

We next asked whether the mechanism by which $\mathrm{CIH}$ exerts its effect on synaptic transmission involves a decrease in presynaptic glutamate release and/or changes in postsynaptic sensitivity to glutamate. One method to address this question relies on examining the mean ${ }^{2} /$ variance $\left(\mathrm{M}^{2} / \sigma^{2}\right)$ of EPSCs, a measure of presynaptic changes in transmitter release attributable to alterations in synaptic efficacy (Malinow and Tsien, 1990; Selig et al., 1995). Manipulations that decrease synaptic efficacy also decrease $\mathrm{M}^{2}$ / $\sigma^{2}$, which is dependent on the number of release sites and release probability (Malinow and Tsien, 1990; Selig et al., 1995). This statistical analysis has recently been successfully applied to horizontal NTS slices to examine presynaptic release (Bailey et al., 2006). Chronic intermittent hypoxia decreased $\mathrm{M}^{2} / \sigma^{2}$ from $134 \pm 32$ (NORM, $n=78$ cells from 49 rats $)$ to $60 \pm 14(10 \mathrm{~d}$ $\mathrm{CIH}, n=62$ cells from 37 rats; $p<0.05$ ), suggesting a presynaptic mechanism of altered transmitter release.

Furthermore, postsynaptic membrane properties were the same between the two groups. The decay constant $\left(\tau_{10-90 \%}\right)$ of the EPSCs were similar between NORM $(5.3 \pm 0.3 \mathrm{~ms} ; n=67)$ and $\mathrm{CIH}$ ( $4.5 \pm 0.3 \mathrm{~ms} ; n=50 ; p>0.05$ vs NORM, $t$ test) rats when fit with a monoexponential function. Resting membrane potential (RMP) was comparable (NORM, $-60.0 \pm 1.4 \mathrm{mV}$ vs $\mathrm{CIH},-56.9 \pm 1.2 \mathrm{mV} ; p>0.05, t$ test) as was input resistance (NORM, $739 \pm 57 \mathrm{M} \Omega$ vs $\mathrm{CIH}, 819 \pm 79 \mathrm{M} \Omega ; p>0.05$, $t$ test).

Cyclothiazide (CTZ), which blocks desensitization of AMPA receptors (Trussell et al., 1993), was applied to slices to examine postsynaptic receptor properties and determine whether they are a source of reduced EPSCs in CIH animals. CTZ significantly increased the decay constants $\left(\tau_{10-90 \%}\right)$ of EPSCs in both animal groups (Fig. 3A). Decay constants increased in NORM rats from $4.3 \pm 0.4$ to $9.1 \pm 0.8 \mathrm{~ms}$ and in $\mathrm{CIH}$ rats from $4.4 \pm 0.6$ to $9.1 \pm$ $1.2 \mathrm{~ms}$, in the presence of CTZ $(p<0.05$, paired $t$ test, both groups) (Fig. 3B). The magnitude of increase in decay times was the same (NORM, $2.28 \pm 0.31$ vs $\mathrm{CIH}, 2.17 \pm 0.23$, from a normalized value of $1.0 ; p>0.05, t$ test) and not accompanied by an augmentation in EPSC amplitude (NORM, $1.14 \pm 0.06$ vs $\mathrm{CIH}, 1.19 \pm 0.06 ; p>0.05, t$ test). CTZ also increased spontaneous EPSC decay comparably in both groups (magnitude change NORM, $1.88 \pm 0.22$ vs CIH, $1.81 \pm 0.23 ; p>0.05, t$ test) (Fig. $3 C)$. These results suggest that the decrease in amplitude of AMPA-mediated EPSCs after CIH is not attributable to increased desensitization of postsynaptic receptors.

mEPSCs were recorded in the presence of TTX $(1 \mu \mathrm{M})$ to further differentiate presynaptic from postsynaptic mechanisms. Analysis of mEPSC frequency provides information about possible changes in the presynaptic release process, whereas changes in the amplitudes of the miniature currents can reflect either alterations in postsynaptic receptor properties or presynaptic neurotransmitter vesicle packet size. An example of NORM and $\mathrm{CIH}$ mEPSCs is shown in Figure $4 A$. The mean amplitude of mEPSCs was not significantly different between NORM $(16.5 \pm 1.9 \mathrm{pA}$; $n=9$ cells, 3 slices, 3 rats $)$ and $10 \mathrm{~d} \mathrm{CIH} \mathrm{(16.9} \pm 1.8 \mathrm{pA} ; n=11$ cells, 4 slices, 4 rats). Amplitude distribution was comparable. Rise time constant $\left(\tau_{10-90 \%}\right)$ in normoxic rats $(1.3 \pm 0.1 \mathrm{~ms})$ was similar to $\mathrm{CIH}$ animals $(1.4 \pm 0.2 \mathrm{~ms})$, as was decay time $\left(\tau_{10-90 \%}\right.$, NORM, $3.4 \pm 0.5 \mathrm{~ms}$ vs $\mathrm{CIH}, 3.9 \pm 0.6 \mathrm{~ms} ; p>0.05)$. The similarity in mEPSC amplitude and kinetics indicate that there is no difference in postsynaptic current attributable to changes in receptor properties or in presynaptic vesicle packet size. Conversely, mEPSC frequency was elevated after CIH (Fig. $4 B$, inset) and associated with a significant leftward shift in the cumulative 
A

NORM

$\mathrm{ClH}$
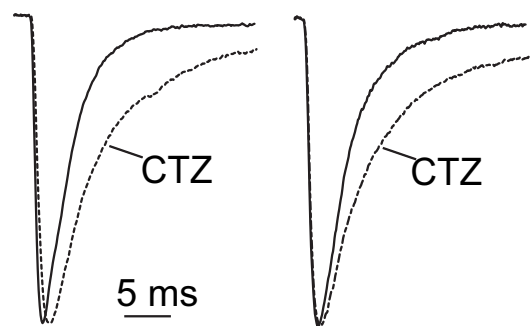

B
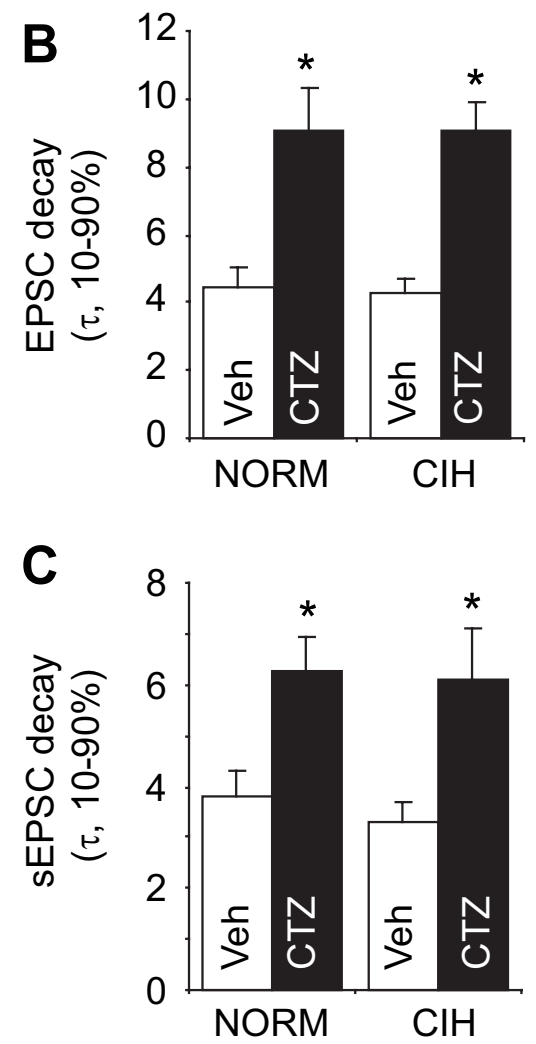

Figure 3. Postsynaptic AMPA receptor desensitization is not altered in $10 \mathrm{~d}$ CIH. $\boldsymbol{A}$, Representative tracings of EPSCs from a NORM (left) and $10 \mathrm{~d}$ CIH (right) rat brainstem slice in the absence and presence of CTZ (dashed lines). NTS cells were voltage clamped at $-60 \mathrm{mV}$, and the TS was stimulated at $0.5 \mathrm{~Hz}$. The normalized average of 18 traces is shown. Note that CTZ substantially increases decay time of NORM and CIH EPSCS. $\boldsymbol{B}$, CTZ increased decay time $\left(\tau_{10}\right.$ $90 \%$ ) by twofold in NORM and ClH slices. The increases in decay times were comparable between the two groups (see Results). C, CTZ also increased the decay times of spontaneous EPSCs (sEPSCs) in NORM and CIH cells in a similar manner. Veh, ACSF vehicle. ${ }^{*} p<0.05, t$ test.

probability of interevent intervals (Fig. $4 B$ ). Thus, the data presented in this section indicate, at a minimum, a presynaptic change in transmitter release. With regard to the reduced amplitude of the evoked response, the postsynaptic membrane and receptor properties appear unchanged.

\section{CIH alters calcium dependence of TS-evoked EPSCs}

A presynaptic mechanism may involve changes in the synaptic proteins involved in the docking and release of synaptic vesicles and/or factors that modulate these processes, one of these being calcium. Exocytosis at most synapses has a steep supralinear dependence on $\mathrm{Ca}^{2+}$ influx (Dodge and Rahamimoff, 1967; Mintz et al., 1995). To assess the mechanism of synaptic depression after $\mathrm{CIH}$, we varied the probability of neurotransmitter release by changing external $\mathrm{Ca}^{2+}$ concentrations from 2 to 0.5 and $4 \mathrm{~mm}(8$ min exposure, order varied between the latter two) and monitoring TS-evoked EPSCs. Increasing external calcium levels from 2 to $4 \mathrm{~mm}\left(\mathrm{Mg}^{2+}\right.$ of $\left.1.2 \mathrm{~mm}\right)$ significantly increased the amplitude of evoked EPSCs (eEPSCs) in NORM but not CIH rats (Fig. 5A). Conversely, reducing calcium levels from 2 to $0.5 \mathrm{mM}\left(\mathrm{Mg}^{2+}\right.$ of 5 $\mathrm{mm}$ ) decreased EPSCs in both groups (Fig. 5A). Responses were reversible. EPSCs at $2 \mathrm{mM} \mathrm{Ca}^{2+}$ were normalized to $100 \%$ for additional analysis. In NORM slices, $4 \mathrm{mM} \mathrm{Ca}^{2+}$ increased EPSC amplitude to $126 \pm 8.2 \%$ of baseline ( $p<0.05$, paired $t$ test), whereas $0.5 \mathrm{mM} \mathrm{Ca}^{2+}$ decreased EPSCs to $39.9 \pm 11.4 \%$ of baseline $(p<0.05$, paired $t$ test $)$ (Fig. $5 B)$. Surprisingly, the amplitude of CIH EPSCs in the presence of $4 \mathrm{mM} \mathrm{Ca}^{2+}$ was $99.8 \pm 8.5 \%$ of that in $2.0 \mathrm{~mm}$ calcium ( $p>0.05$, paired $t$ test) but $36.5 \pm 3.7 \%$ of baseline during $0.5 \mathrm{mM} \mathrm{Ca}^{2+}(p<0.05$, paired $t$ test $)$. During exposure to $0.5 \mathrm{mM} \mathrm{Ca}{ }^{2+}$, the percentage of failures in NORM cells was $13 \pm 7 \%(n=7)$, whereas it was $32 \pm 8 \%(n=11)$ in $\mathrm{CIH}$ rats.

The lack of an increase in EPSC amplitude in CIH slices in the presence of $4 \mathrm{mM} \mathrm{Ca}^{2+}$ is not attributable to the inability of calcium to enter the cell. In contrast to results obtained during evoked transmission, $4 \mathrm{mM} \mathrm{Ca}^{2+}$ elevated the frequency of spontaneous EPSCs in both NORM and CIH groups. EPSC frequency increased in NORM slices from $5.0 \pm 1.4$ to $7.4 \pm 1.7 \mathrm{~Hz}$ and in $\mathrm{CIH}$ slices from $7.5 \pm 1.1$ to $9.9 \pm 1.3 \mathrm{~Hz}$ (both groups, $p<0.05$, paired $t$ test).

In the NTS, repetitive TS stimulation induces EPSC depression after the initial current response (Miles, 1986; Kline et al., 2002) that is postulated to be determined by vesicular dynamics and intracellular calcium (Schild et al., 1995). We analyzed the paired-pulse ratios (PPR $=$ EPSC2/EPSC1) of two consecutive EPSCs (interstimulus interval, $20 \mathrm{~ms}$ ) in 4,2 , and $0.5 \mathrm{mM} \mathrm{Ca}^{2+}$ to determine whether there were fundamental differences in presynaptic release or postsynaptic sensitivity between NORM and $\mathrm{CIH}$ rats (Zucker and Regehr, 2002). Under physiological calcium, the mean PPR was similar between control and $\mathrm{CIH}$ rats (control, $0.57 \pm 0.08, n=10$ vs $\mathrm{CIH}, 0.47 \pm 0.07, n=12 ; p>$ $0.05)$. Lowering external calcium levels to $0.5 \mathrm{~mm}$ reversed the EPSC ratio from depression to facilitation in NORM and $\mathrm{CIH}$ slices (Fig. 5C,D). In NORM slices, the PPR increased to $1.16 \pm$ 0.23 ( $p=0.02$ vs $2 \mathrm{~mm}$, paired $t$ test; $n=6$, a $220 \pm 36 \%$ increase). In $\mathrm{CIH}$ slices, reducing calcium levels increased the PPR to $1.13 \pm 0.18$ ( $p=0.003$ vs $2 \mathrm{mM}$, paired $t$ test; $n=6$, a $280 \pm 59 \%$ increase). The increase in the PPR was anticipated based on previous studies by others examining the effect of reduction in calcium on the PPR (Pinco and Lev-Tov, 1993; Zucker and Regehr, 2002; Kravchenko et al., 2006). Failures in EPSC1 or EPSC2 were included in this PPR analysis. Additional analysis of the number of failures in the first and second EPSC of the PPR demonstrated that the number of failures in EPSC1 and EPSC2 was greater under $0.5 \mathrm{~mm}$ calcium in $\mathrm{CIH}$ rats compared with NORM (Fig. 5E). Greater failure rates in CIH slices were not attributable to signal-to-noise issues, because the RMS noise was comparable (NORM, $2.20 \pm 0.49$ pA vs $\mathrm{CIH}, 1.86 \pm 0.34 \mathrm{pA} ; p=$ $0.562, t$ test). These results demonstrate a lower tolerance of exocytosis to low calcium in $\mathrm{CIH}$ slices.

CIH does not eliminate frequency-dependent depression We examined synaptic transmission during the stimulus train that facilitated action potential discharge (30 stimuli at $20 \mathrm{~Hz}$ ) (Fig. 1). Although in $\mathrm{CIH}$ the amplitude of the evoked synaptic 
response is reduced, repetitive TS stimulation elicited frequency-dependent depression in both NORM and $10 \mathrm{~d}$ CIH cells (NORM, $n=19$; CIH, $n=17$ ) (Fig. 6). Additionally, as shown in Figure 6, a greater proportion of $\mathrm{CIH}$ slices exhibited a high degree of asynchronous release during and after the stimulus train (NORM, 0.35 vs $\mathrm{CIH}, 0.65 ; p=0.059, z$ test). The latter analysis included cells in which the amount of asynchronous release prohibited determination of EPSC amplitudes at the end of the train (NORM, $n=1 ; \mathrm{CIH}$, $n=3)$.

\section{Asynchronous activity is sufficient to induce action potential discharge}

We demonstrated that $\mathrm{CIH}$ increases spontaneous action potential discharge (Fig. 1) and asynchronous transmitter release (Fig. 6). To directly link aEPSCs to AP discharge, we recorded membrane potential in response to injection of $2 \mathrm{~s}$ of asynchronous current (similar time course as observed in Fig. 1). This current was an average activity previously recorded from a $\mathrm{CIH}$ slice (Fig. 6). Current injection was done in the presence of NBQX $(10 \mu \mathrm{M})$ and bicuculline $(10 \mu \mathrm{M})$ to eliminate influence from spontaneous excitatory or inhibitory network activity. Injecting $2 \mathrm{~s}$ of asynchronous current depolarized membrane potential and increased AP discharge in NORM and CIH slices. An example of such a recording is shown in Figure 7. The proportion of NORM and CIH slices that responded to physiological stimulus was the same (NORM, $0.625, n=5$ vs CIH, 0.642, $n=9 ; p>$ $0.05)$. The number of evoked action potentials was also comparable (NORM, $7.6 \pm 2.3, n=5$ vs $\mathrm{CIH}, 13.1 \pm 3.1, n=9$; $p=$ 0.22 ). These results suggest comparable postsynaptic membrane properties between the two groups. Similar postsynaptic properties were confirmed by examining action potentials in response to current steps from $-60 \mathrm{mV}$ in the presence of NBQX and bicuculline. NORM and CIH slices illustrated comparable AP threshold $(-41.3 \pm 2.8$ vs $-43.9 \pm 2.2 \mathrm{mV})$, absolute amplitude $(72.4 \pm 2.0$ vs $74.8 \pm 2.3 \mathrm{mV})$, and afterhyperpolarization $(-52.5 \pm 2.5$ vs $-50.8 \pm 2.3 \mathrm{mV})$. Together, the results demonstrate that increased asynchronous spontaneous EPSCs in $\mathrm{CIH}$ slices are sufficient to increase AP discharge in $\mathrm{CIH}$ slices.

\section{CaMKII mediates CIH depression}

The relationship between CaMKII, calcium, and neurotransmission at the synapse led us to investigate the role of CaMKII in $\mathrm{CIH}$. Increases in calcium can activate several signaling pathways, such as CaMKII, which is a multifunctional calcium-dependent kinase present in the presynaptic and postsynaptic cell (Lisman et al., 2002). Activation of CaMKII acts as a molecular switch to trigger long-term changes in synaptic strength, such as long-term potentiation and depression (Stanton and Gage, 1996; Margrie et al., 1998; Lisman et al., 2002). We examined the role of CaMKII in $\mathrm{CIH}$-induced depression. Bath application of the nonspecific kinase inhibitor H-7 [1-(5-isoquinolinesulfonyl)-2-methylpiperazine dihydrochloride] (100 $\mu \mathrm{M}, 15 \mathrm{~min})$, which blocks several kinases but is a poor blocker of CaMKII (Hidaka et al., 1984; Leahy and Vallano, 1991; Belmeguenai and Hansel, 2005; Lu and Hawkins, 2006), did not alter EPSCs elicited at $0.5 \mathrm{~Hz}$ in NORM $(99.3 \pm 6.1 \%$ of baseline; $n=5)$ or $\mathrm{CIH}(98.3 \pm 9.4 \%$ of baseline; $n=5)$ animals. Bath application of the CaMKII inhibitor KN-62 (1-[ $N, O$-bis(5-isoquinolinesulphonyl)- $N$-methyl-L-tyrosyl $]-4$ phenylpiperazine] (3.5 $\mu \mathrm{M}, 10 \mathrm{~min})$ differentially affected evoked EPSCs in NORM and CIH rats (Fig. $8 A$ ). In NORM slices, $\mathrm{KN}-62$ did not change EPSC amplitude (106.2 $\pm 9.0 \%$ of baseline; $p>$ 0.05 , paired $t$ test; $n=4$ ) (Fig. $8 B$ ). In contrast, in CIH slices, KN-62 significantly increased the amplitude of EPSCs to $148.8 \pm$ $32 \%$ of baseline. EPSCs rose from $106 \pm 61$ to $142.7 \pm 59 \mathrm{pA}$ $(p<0.05$, paired $t$ test; $n=4)$ (Fig. $8 B$ ). CaMKII did not alter input resistance (baseline, $257 \pm 73 \mathrm{M} \Omega$ vs CaMKII, $251 \pm 72$ $\mathrm{M} \Omega ; p>0.05$, paired $t$ test). Although the increase in amplitude was a robust response, changes in the amplitude and frequency of the spontaneous EPSCs in the presence of the inhibitor were variable in $\mathrm{CIH}$.

To confirm an increase in CaMKII activity after $\mathrm{CIH}$, we performed Western blots of tissue lysates for CaMKII and phosphorylated Thr286 CaMKII in CIH and NORM tissue. As seen in Figure $8 C$, anti-CaMKII protein $(50 \mathrm{kDa})$ was comparable between NORM and CIH in the NTS and sensory ganglia, the cell bodies for presynaptic afferents. Conversely, CIH increased antiphosphorylated Thr286 CaMKII protein compared with NORM (Fig. 8D). Phosphorylated CaMKII increased in the NTS and sensory ganglia neurons, suggesting that a portion of the former represents a change in presynaptic protein. Multiple bands may represent additional phosphorylated sites of the enzyme (Bennett et al., 1983; Kuret and Schulman, 1985; Lou et al., 1986; Hudmon et al., 1996; Mengesdorf et al., 2002). Densitometry was performed directly from the membrane using the Storm PhosphorImager. Analysis of band density demonstrated that CaMKII protein was comparable after CIH in NTS $(1.03 \pm 0.07$ of NORM; $p>0.05, t$ test). In sensory ganglia, CaMKII protein decreased $(0.90 \pm 0.02$ of NORM; $p<0.05, t$ test $)$. This decrease in CaMKII in sensory ganglia coincides with the large increase in phosphorylated $\alpha$-CaMKII after CIH $(1.43 \pm 0.01$ of NORM; $p<0.01, t$ test). Phosphorylated CaMKII protein in NTS also increased $(1.12 \pm 0.02$ of NORM; $p<0.05, t$ test $)$.

\section{Discussion}

We demonstrated that $10 \mathrm{~d} \mathrm{CIH}$ increases information transfer between chemosensory afferents and NTS second-order neurons 


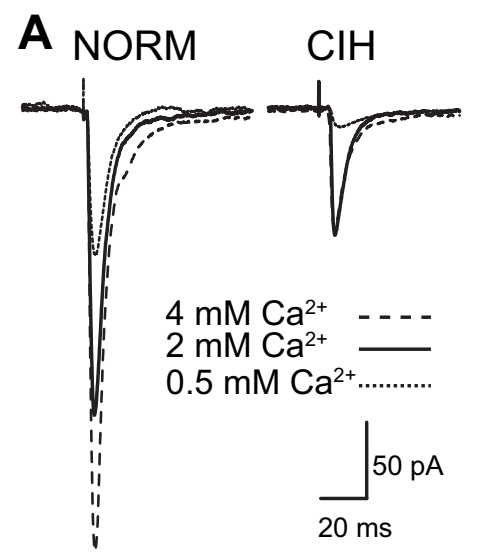

B

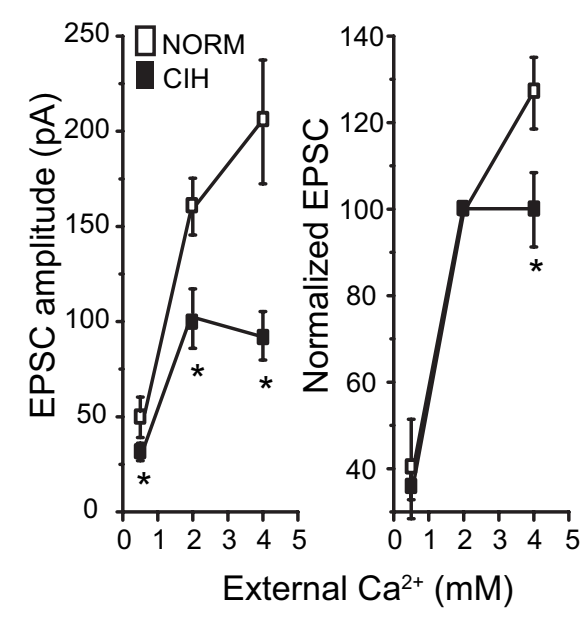

External $\mathrm{Ca}^{2+}(\mathrm{mM})$
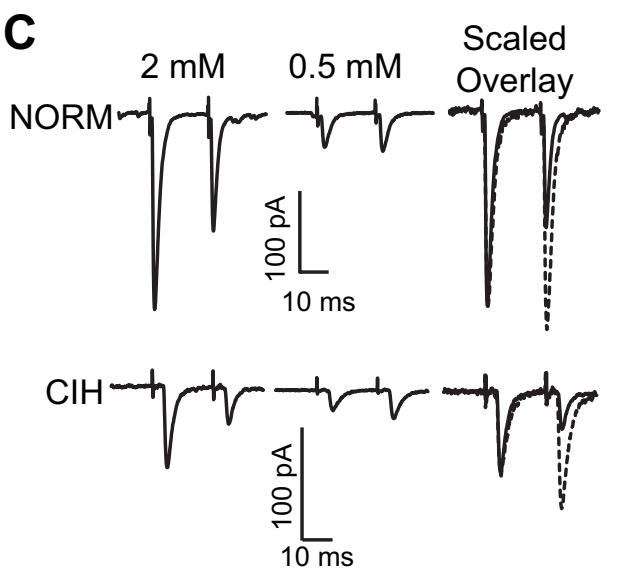

D

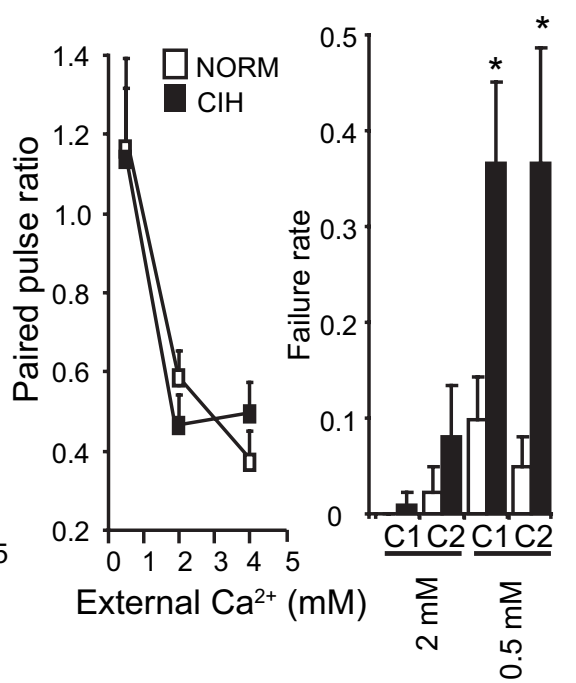

Figure 5. Ten days of CIH alters the calcium dependence of EPSCS. A, Representative tracings of EPSCS from a NORM (left) and $10 \mathrm{~d}$ CIH (right) slice during three external calcium concentrations. Traces are the average of 18 currents. In NORM slices, EPSC amplitude substantially increases during $4 \mathrm{~mm}$ external calcium (dashed line), whereas $0.5 \mathrm{~mm}$ calcium (dotted line) reduces EPSC amplitude. After hypoxia, $\mathrm{ClH}$ slices fail to increase current amplitude during higher calcium concentrations yet dramatically decrease EPSC amplitude during low concentrations. B, EPSC amplitude is plotted against external calcium concentrations (left). CIH EPSCS were minimally affected during elevated calcium, whereas $0.5 \mathrm{~mm}$ depressed EPSCS. NORM EPSCs responded to both calcium concentrations. EPSCS at $2 \mathrm{~mm} \mathrm{Ca}{ }^{2+}$ were normalized for additional analysis (right) and demonstrate a comparable response on EPSC amplitude during reduced calcium concentrations. C, Representative tracings of two consecutive EPSCs from a NORM (top) and $10 \mathrm{~d}$ CIH (bottom) slice during physiological ( $2 \mathrm{~mm}$; left) and $0.5 \mathrm{~mm}$ (middle) external calcium concentrations. Overlay of the paired pulses during 2 and $0.5 \mathrm{~mm}$ is shown on the right and scaled to the first pulse during $2 \mathrm{~mm}$. Examples represent the average of 20 current traces. As shown, decreasing external calcium resulted in the paired-pulse ratio converting from depression to facilitation. $\boldsymbol{D}$, Plotting the paired-pulse ratio to 4, 2, and $0.5 \mathrm{~mm}$ external calcium illustrates that raising external calcium levels in CIH slices has little effect on the ratio when compared with $2 \mathrm{~mm}$. In NORM slices, the ratio is reduced (more depression in the second EPSC). Low calcium levels increase the ratio in both groups in a comparable manner. $\boldsymbol{E}$, Number of failures observed in either the first or second EPSC ( $C 1$ and C2, respectively) of the paired-pulse ratio during 2 and $0.5 \mathrm{~mm}$ external calcium. Although the paired-pulse ratio was comparable between the two groups, the number of failures in either EPSC was significantly greater during $0.5 \mathrm{~mm}$ calcium in CIH compared with NORM.

by augmentation of spontaneous presynaptic neurotransmitter release during and after a stimulus train and through a basal increase in miniature activity that provides a tonic excitatory influence. This is counterbalanced by depression of evoked synaptic currents.

We propose that the decrease in evoked EPSC amplitude after $\mathrm{CIH}$ is an adaptive response to fine tune and maintain stable respiratory parameters during increased sensory afferent activity. That is, the NTS network attempts to balance the increase in excitatory sensory input by scaling evoked synaptic transmission downward. Thus, this novel form of homeostatic plasticity would ensure the proper functioning of the respiratory control system during $\mathrm{CIH}$.

\section{Role of NTS during CIH}

Both clinical and experimental evidence demonstrate that the autonomic alterations in OSAS and its CIH animal models originate from the peripheral chemoreflex (Fletcher, 2001; Prabhakar and Kline, 2002). In our model of $\mathrm{CIH}$, there is an increase in baseline discharge of chemoreceptor afferent fibers at normal oxygen levels and an exaggerated increase in the response of the chemoreceptor fibers to each hypoxic episode (Peng et al., 2003). This chemosensory activity is transmitted to the NTS in which it is processed to regulate breathing and blood pressure (Andresen and Kunze, 1994). An increase in the gain of the central component of chemoreceptor processing on respiration after $\mathrm{CIH}$ has been demonstrated (Ling et al., 2001). In those studies, carotid sinus nerve stimulation, which bypasses the carotid body input, was more effective in activating phrenic nerve discharge in $\mathrm{CIH}$ than normoxic rats. As one mechanism for this central effect, we demonstrated that $\mathrm{CIH}$ increases baseline NTS second-order neuron activity and has an even more pronounced effect on discharge after a stimulus train. This would contribute to an increase excitatory input to downstream cardiorespiratory pathways.

\section{CIH-induced changes in} synaptic transmission

The events we describe in this study have occurred after $10 \mathrm{~d}$ CIH. Two changes that appear to be paradoxical stand out. The first can be attributed to a presynaptic mechanism(s). CIH neurons show an increase in frequency of mEPSCs and aEPSCs. This increase in transmitter release is sufficient to elicit APs in the postsynaptic cells. The second interesting effect of $\mathrm{CIH}$ is a large reduction in eEPSC amplitude. This, we believe, also has a presynaptic origin based on the reduced $\mathrm{M}^{2}$ / $\sigma^{2}$, increased failure rate, and altered synaptic efficiency during increases in external calcium concentrations. Parallel changes in $\mathrm{M}^{2} / \sigma^{2}$ and EPSC amplitudes are classically attributed to presynaptic effects attributable to changes in quantal content, either as a result of the reduction in the probability of transmitter release or the number of release sites (Malinow and Tsien, 1990; Selig et al., 1995). The lack of effect of raising calcium on eEPSCs in CIH neurons at the same time that spontaneous release is increased suggests that either a calcium-dependent component of evoked, but not the spontaneous, release machinery has been altered or $\mathrm{CIH}$ modifies calcium intracellular buffering, extrusion, or channel activity at 
the evoked release site. Regardless, results suggest an alteration of one or more proteins responsible for transmitter release.

We also addressed a possible postsynaptic mechanism. There were no differences in postsynaptic cell input resistance or RMP, which could lead to a change in the response to transmitter release. Decreases in eEPSCs after $\mathrm{CIH}$ do not result from changes in AMPA receptor properties. Comparable EPSC kinetics and CTZ responses indicate that postsynaptic receptor sensitivity was not decreased. The lack of change in mEPSC amplitude distribution in CIH suggests that AMPA receptor clusters were not removed from the postsynaptic membrane.

\section{CIH models}

At present, more than one working hypothesis can be generated to explain our results. In any case, it is likely that changes in several components of the release process are involved in the effect of CIH. Here we suggest two models, both of which implicate altered calcium regulation of transmitter release. One model would require differential regulation of the pools of vesicles responsible for evoked and spontaneous transmitter release. One might expect that attenuation in evoked synaptic transmission attributable to changes in release probability would also reduce miniature frequency. However, miniature and asynchronous release was greater in $\mathrm{CIH}$ rather than reduced. Directionally different results have been observed previously in which a decrease in evoked EPSP/EPSCs or endplate potentials is accompanied by increases or unaltered miniature events (Eliot et al., 1994; Zengel and Sosa, 1994; Cummings et al., 1996; Pan et al., 1996). We propose that the effects of $\mathrm{CIH}$ on the frequency of mEPSCs and aEPSCs versus the eEPSCs reflect differential regulation of release of two vesicular pools. Previous work indicates that mEPSCs may arise from a pool of readily releasable vesicles distinct from those released by neural activity (Zengel and Sosa, 1994; Sara et al., 2005). Mice lacking synaptobrevin (Schoch et al., 2001) and SNAP-25 (synaptosome-associated protein of $25 \mathrm{kDa}$ ) (Washbourne et al., 2002) have reduced evoked synaptic transmission but have considerable miniature events. Differences in specific calcium channels responsible for evoked and spontaneous release events have been demonstrated. Recordings from neurons in spinal laminas I and II demonstrated that eEPSCs were sensitive to blockers of high-threshold calcium currents, whereas the mEPSCs were blocked by low-threshold calcium channel antagonists (Bao et al., 1998). In the rat hippocampus, phorbol esters induced an increase in miniature frequency that was attenuated by L-type channel blockers, whereas the evoked response was $\omega$-conotoxin (N-type) sensitive (Parfitt and Madison, 1993). Several highthreshold calcium and T-type calcium channels are present in visceral sensory (Mendelowitz and Kunze, 1992) and chemosensory (D. L. Kunze and D. M. Katz, unpublished observation) neurons. Although the evoked EPSC at the NTS synapse is blocked by $\omega$-conotoxin (Mendelowitz et al., 1995), the role of specific calcium channels in eliciting spontaneous activity has not been addressed.

Recent studies on the relationship between CaMKII and calcium channels at the synapse led us to investigate the role of CaMKII in CIH. Mutant mouse studies demonstrated that en-
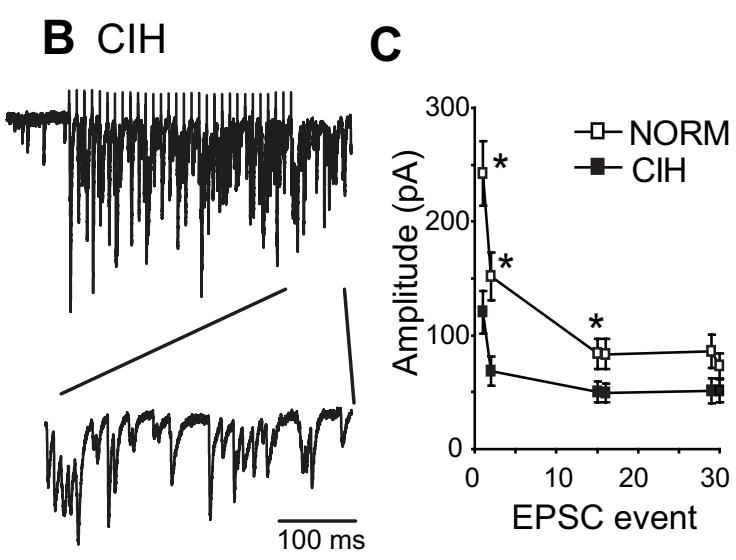

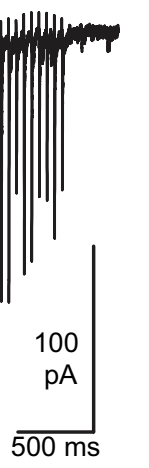

ng repetitive TS stimulation. Representative Figure 6. Ten day CIH synapses have exaggerated asynchronous release during repetitive TS stimulation. Representative
tracing of EPSCs from a NORM $(\boldsymbol{A})$ and $10 \mathrm{~d} \mathrm{CIH}(\boldsymbol{B})$ slice during repetitive stimulation $(20 \mathrm{~Hz}, 30$ episodes). An increase in asynchronous release was more readily observed in $\mathrm{CIH}$ than NORM. An extended timescale illustrating asynchronous release in CIH traces is presented on the bottom of $\boldsymbol{B}$. C, EPSC amplitude of events 1, 2, 15, 16, 29, and 30 in NORM and CIH cells during repetitive stimulation. Both groups exhibited frequency-dependant depression.

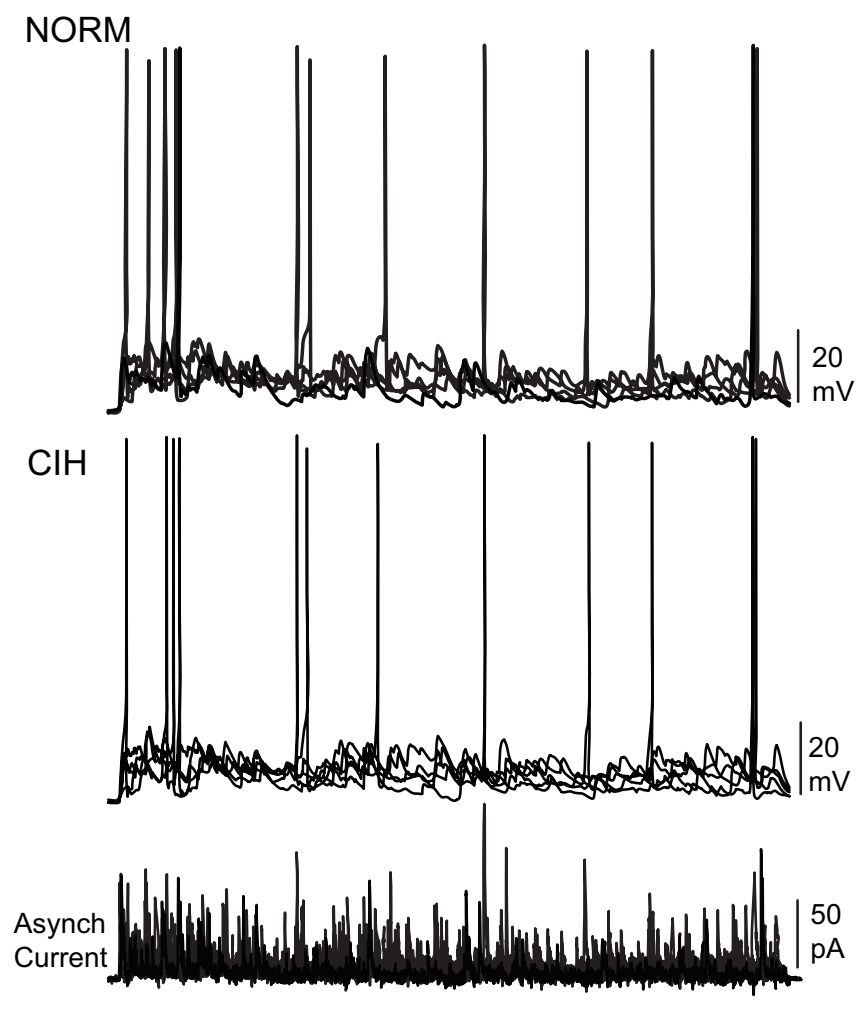

Figure 7. Asynchronous activity induces action potential firing in NORM and CIH slices. Representative tracings of aEPSC evoked action potentials in NORM (top) and CIH (middle) slices. Injected asynchronous current (bottom) was recorded from a CIH slice and represents an average response. Shown is an overlay of five traces. Note the comparable AP discharge between the two groups.

dogenous presynaptic CaMKII dampens synaptic transmission (Chapman et al., 1995; Mayford et al., 1995; Hinds et al., 2003). CaMKII in the presynaptic terminal can phosphorylate several proteins involved in neurotransmitter release such as synapsin (Llinas et al., 1991), rabphilin-3A (Sudhof, 1995), synaptotagmin (Popoli, 1993), and N-type calcium channels (Yokoyama et al., 1997). CaMKII phosphorylation of N-type channels disrupts its interaction with synaptic vesicle proteins to reduce evoked neurotransmitter release while increasing asynchronous release 


\section{A NORM $\quad \mathrm{ClH}$}

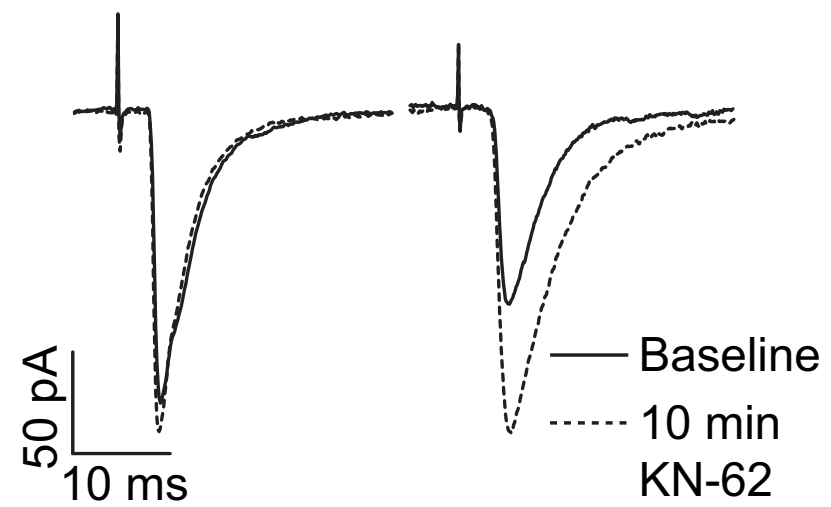

B

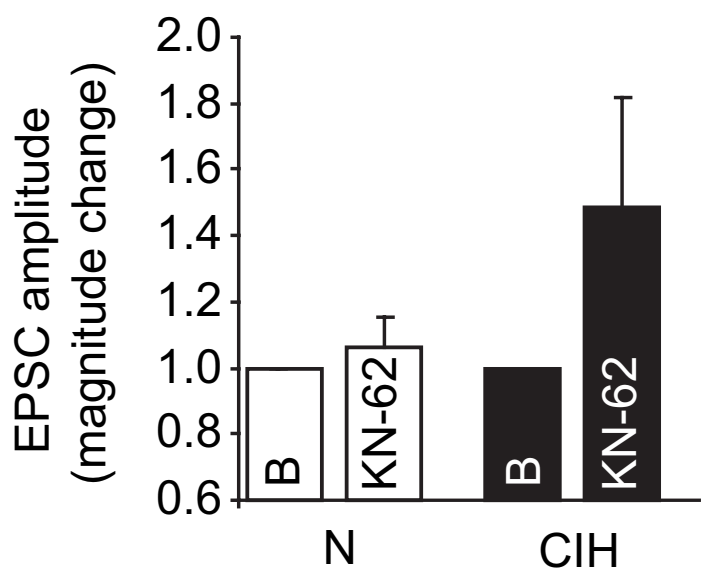

C CaMKII

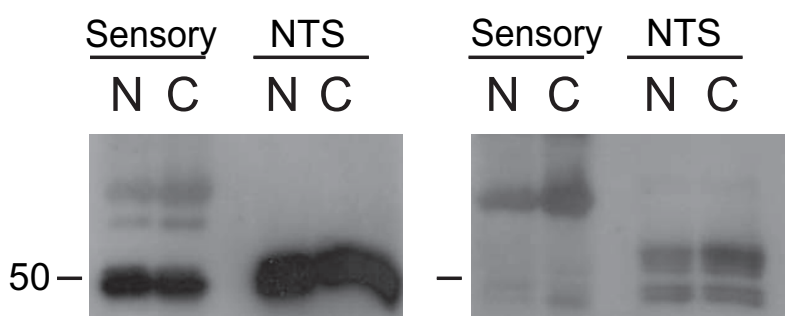

Figure 8. CaMKIl activation after $10 \mathrm{~d}$ CIH leads to EPSC depression. $\boldsymbol{A}$, Representative tracings of EPSCs from a NORM (left) and $10 \mathrm{~d}$ CIH (right) slice in the absence and presence of KN-62 (dashed line). Baseline current traces are distinguished by the solid line. NTS cells were voltage clamped at $-60 \mathrm{mV}$, and the TS was stimulated at $0.5 \mathrm{~Hz}$. Examples illustrated represent the average of 18 traces. Note the greater increase in EPSC amplitude after KN-62 application in $\mathrm{CIH}$ slices than NORM. $\boldsymbol{B}$, Magnitude of EPSC amplitude change in NORM (N) and CIH slices during baseline (B) and $10 \mathrm{~min} \mathrm{KN}-62$. Note the increase in currents in $\mathrm{CIH}$ but not NORM slices. $\mathrm{C}$, Western blot analysis illustrates that $\alpha$ CaMKII protein did not increase in $\mathrm{CIH} \mathrm{(C)} \mathrm{compared} \mathrm{with}$ NORM (N) in sensory ganglia or NTS. D, Conversely, phosphorylated $\alpha$ CaMKII is upregulated in CIH (C) compared with NORM (N) in presynaptic sensory ganglia and the NTS. Protein molecular weight (in kilodaltons) is shown to the left of the blots.

(Mochida et al., 1996; Rettig et al., 1997; Harkins et al., 2004). In $\mathrm{CIH}$, the increased eEPSC amplitude to CaMKII blockade with $\mathrm{KN}-62$ in the absence of changes in input resistance suggests a similar presynaptic mechanism. In contrast, a postsynaptic action of CaMKII generally favors membrane insertion of AMPA receptors to increase the synaptic response rather than decrease it (Poncer et al., 2002). It should be noted that KN-62 may also inhibit CaMKIV/V (Hidaka and Yokokura, 1996). Western blot analysis confirmed an increase in phospho-CaMKII after CIH. Data are compatible with computational studies indicating that CaMKII activity could last for weeks (Lisman et al., 2002; Miller et al., 2005).

L-Type and T-type channels are also regulated by CaMKII. The activation curve for T-type channels is shifted in the hyperpolarizing direction during CaMKII activation, which would be expected to increase calcium influx at RMP (Welsby et al., 2003). The L-type channel is also activated by CaMKII (Hudmon et al., 2005). In our model, the upregulation of CaMKII in CIH would act differentially on vesicle pools associated with specific calcium channel subtypes. Thus, association of T-type or L-type channels with spontaneous release would lead to increased activity with CIH.

We also considered a second model of a depolarized presynaptic terminal with an increased baseline of calcium influx that raises intracellular calcium to augment spontaneous release. The increase in spontaneous release depletes vesicles available for evoked release and reduces the amplitude of the evoked response. This would require an additional mechanism(s) to explain the increase in the evoked response with the CaMKII inhibitor in $\mathrm{CIH}$.

\section{Limitations}

We examined in vitro neurotransmission after in vivo exposure to $\mathrm{CIH}$. We believe our results derive from the adaptation of neural activity to $\mathrm{CIH}$ rather than the preparation of slices or a consequence of the final hypoxic episode. Although acute hypoxia reversibly increases miniature release, decreases evoked neurotransmission, or alters ion channel function (Luhmann and Heinemann, 1992; Fleidervish et al., 2001; Pascual et al., 2002), all slices were generated and examined under similar conditions and timeframe to minimize potential influences.

\section{Relevance}

Our results are reminiscent of studies examining homeostatic plasticity and activity-dependent changes in neuronal function in other central cells (Davis and Bezprozvanny, 2001; Turrigiano and Nelson, 2004). We extend the concept of homeostatic plasticity to the autonomic nervous system, whose natural function is to maintain systemic homeostasis. Breathing instability, such that occurs in OSA, Cheyne-Stokes, and Biot breathing, is often observed in the clinic and may be initiated by increased chemoreceptor activity (Cherniack and Longobardo, 1986). Our results suggest that the decrease in synaptic transmission between chemosensory afferents and NTS neurons is one mechanism in which the respiratory system adapts to minimize breathing instability and its associated deleterious effects.

\section{References}

Andresen MC, Kunze DL (1994) Nucleus tractus solitarius-gateway to neural circulatory control. Annu Rev Physiol 56:93-116.

Andresen MC, Yang MY (1990) Non-NMDA receptors mediate sensory afferent synaptic transmission in medial nucleus tractus solitarius. Am J Physiol 259:H1307-H1311.

Bailey TW, Jin YH, Doyle MW, Smith SM, Andresen MC (2006) Vasopressin inhibits glutamate release via two distinct modes in the brainstem. J Neurosci 26:6131-6142.

Bao J, Li JJ, Perl ER (1998) Differences in $\mathrm{Ca}^{2+}$ channels governing generation of miniature and evoked excitatory synaptic currents in spinal laminae I and II. J Neurosci 18:8740-8750.

Belmeguenai A, Hansel C (2005) A role for protein phosphatases 1,2A, and 2B in cerebellar long-term potentiation. J Neurosci 25:10768-10772.

Bennett MK, Erondu NE, Kennedy MB (1983) Purification and character- 
ization of a calmodulin-dependent protein kinase that is highly concentrated in brain. J Biol Chem 258:12735-12744.

Chapman PF, Frenguelli BG, Smith A, Chen CM, Silva AJ (1995) The alpha$\mathrm{Ca}^{2+} /$ calmodulin kinase II: a bidirectional modulator of presynaptic plasticity. Neuron 14:591-597.

Cherniack NS, Longobardo GS (1986) Abnormalities in respiratory rhythm. In: Handbook of physiology. The respiratory system. Control of breathing. (Cherniack NS, Widdicombe JG, eds), pp 729-750. Bethesda, MD: American Physiological Society.

Cummings DD, Wilcox KS, Dichter MA (1996) Calcium-dependent paired-pulse facilitation of miniature EPSC frequency accompanies depression of EPSCs at hippocampal synapses in culture. J Neurosci 16:5312-5323.

Davis GW, Bezprozvanny I (2001) Maintaining the stability of neural function: a homeostatic hypothesis. Annu Rev Physiol 63:847-869.

Dodge Jr FA, Rahamimoff R (1967) Co-operative action a calcium ions in transmitter release at the neuromuscular junction. J Physiol (Lond) 193:419-432.

Doyle MW, Andresen MC (2001) Reliability of monosynaptic sensory transmission in brain stem neurons in vitro. J Neurophysiol 85:22132223.

Dwinell MR, Powell FL (1999) Chronic hypoxia enhances the phrenic nerve response to arterial chemoreceptor stimulation in anesthetized rats. J Appl Physiol 87:817-823.

Eliot LS, Kandel ER, Hawkins RD (1994) Modulation of spontaneous transmitter release during depression and posttetanic potentiation of Aplysia sensory-motor neuron synapses isolated in culture. J Neurosci 14:3280-3292.

Fleidervish IA, Gebhardt C, Astman N, Gutnick MJ, Heinemann U (2001) Enhanced spontaneous transmitter release is the earliest consequence of neocortical hypoxia that can explain the disruption of normal circuit function. J Neurosci 21:4600-4608.

Fletcher EC (2001) Invited review: physiological consequences of intermittent hypoxia: systemic blood pressure. J Appl Physiol 90:1600-1605.

Harkins AB, Cahill AL, Powers JF, Tischler AS, Fox AP (2004) Deletion of the synaptic protein interaction site of the N-type (CaV2.2) calcium channel inhibits secretion in mouse pheochromocytoma cells. Proc Natl Acad Sci USA 101:15219-15224.

Hidaka H, Yokokura H (1996) Molecular and cellular pharmacology of a calcium/calmodulin-dependent protein kinase II (CaM kinase II) inhibitor, $\mathrm{KN}-62$, and proposal of CaM kinase phosphorylation cascades. Adv Pharmacol 36:193-219.

Hidaka H, Inagaki M, Kawamoto S, Sasaki Y (1984) Isoquinolinesulfonamides, novel and potent inhibitors of cyclic nucleotide dependent protein kinase and protein kinase C. Biochemistry 23:5036-5041.

Hinds HL, Goussakov I, Nakazawa K, Tonegawa S, Bolshakov VY (2003) Essential function of alpha-calcium/calmodulin-dependent protein kinase II in neurotransmitter release at a glutamatergic central synapse. Proc Natl Acad Sci USA 100:4275-4280.

Housley GD, Sinclair JD (1988) Localization by kainic acid lesions of neurones transmitting the carotid chemoreceptor stimulus for respiration in rat. J Physiol (Lond) 406:99-114.

Hudmon A, Aronowski J, Kolb SJ, Waxham MN (1996) Inactivation and self-association of $\mathrm{Ca}^{2+} /$ calmodulin-dependent protein kinase II during autophosphorylation. J Biol Chem 271:8800-8808.

Hudmon A, Schulman H, Kim J, Maltez JM, Tsien RW, Pitt GS (2005) CaMKII tethers to L-type $\mathrm{Ca}^{2+}$ channels, establishing a local and dedicated integrator of $\mathrm{Ca}^{2+}$ signals for facilitation. J Cell Biol 171:537-547.

Kline DD, Takacs KN, Ficker E, Kunze DL (2002) Dopamine modulates synaptic transmission in the nucleus of the solitary tract. J Neurophysiol 88:2736-2744.

Kravchenko MO, Moskalyuk AO, Fedulova SA, Veselovsky NS (2006) Calcium-dependent changes of paired-pulse modulation at single GABAergic synapses. Neurosci Lett 395:133-137.

Kuret J, Schulman H (1985) Mechanism of autophosphorylation of the multifunctional $\mathrm{Ca}^{2+} /$ calmodulin-dependent protein kinase. J Biol Chem 260:6427-6433.

Leahy JC, Vallano ML (1991) Differential effects of isoquinolinesulfonamide protein kinase inhibitors on CA1 responses in hippocampal slices. Neuroscience 44:361-370.

Ling L, Fuller DD, Bach KB, Kinkead R, Olson Jr EB, Mitchell GS (2001)
Chronic intermittent hypoxia elicits serotonin-dependent plasticity in the central neural control of breathing. J Neurosci 21:5381-5388.

Lisman J, Schulman H, Cline H (2002) The molecular basis of CaMKII function in synaptic and behavioural memory. Nat Rev Neurosci 3:175-190.

Llinas R, Gruner JA, Sugimori M, McGuinness TL, Greengard P (1991) Regulation by synapsin I and $\mathrm{Ca}^{2+}$-calmodulin-dependent protein kinase II of the transmitter release in squid giant synapse. J Physiol (Lond) 436:257-282.

Lou LL, Lloyd SJ, Schulman H (1986) Activation of the multifunctional $\mathrm{Ca}^{2+} /$ calmodulin-dependent protein kinase by autophosphorylation: ATP modulates production of an autonomous enzyme. Proc Natl Acad Sci USA 83:9497-9501.

Lu FM, Hawkins RD (2006) Presynaptic and postsynaptic $\mathrm{Ca}^{2+}$ and CamKII contribute to long-term potentiation at synapses between individual CA3 neurons. Proc Natl Acad Sci USA 103:4264-4269.

Luhmann HJ, Heinemann U (1992) Hypoxia-induced functional alterations in adult rat neocortex. J Neurophysiol 67:798-811.

Malinow R, Tsien RW (1990) Presynaptic enhancement shown by wholecell recordings of long-term potentiation in hippocampal slices. Nature 346:177-180.

Margrie TW, Rostas JA, Sah P (1998) Presynaptic long-term depression at a central glutamatergic synapse: a role for CaMKII. Nat Neurosci $1: 378-383$.

Mayford M, Wang J, Kandel ER, O’Dell TJ (1995) CaMKII regulates the frequency-response function of hippocampal synapses for the production of both LTD and LTP. Cell 81:891-904.

McGuire M, Zhang Y, White DP, Ling L (2003) Chronic intermittent hypoxia enhances ventilatory long-term facilitation in awake rats. J Appl Physiol 95:1499-1508.

Mendelowitz D, Kunze DL (1992) Characterization of calcium currents in aortic baroreceptor neurons. J Neurophysiol 68:509-517.

Mendelowitz D, Reynolds PJ, Andresen MC (1995) Heterogeneous functional expression of calcium channels at sensory and synaptic regions in nodose neurons. J Neurophysiol. 73:872-875.

Mengesdorf T, Althausen S, Mies G, Olah L, Paschen W (2002) Phosphorylation state, solubility, and activity of calcium/calmodulin-dependent protein kinase II alpha in transient focal ischemia in mouse brain. Neurochem Res 27:477-484.

Miles R (1986) Frequency dependence of synaptic transmission in nucleus of the solitary tract in vitro. J Neurophysiol 55:1076-1090.

Miller P, Zhabotinsky AM, Lisman JE, Wang XJ (2005) The stability of a stochastic CaMKII switch: dependence on the number of enzyme molecules and protein turnover. PLoS Biol 3:e107.

Mintz IM, Sabatini BL, Regehr WG (1995) Calcium control of transmitter release at a cerebellar synapse. Neuron 15:675-688.

Mochida S, Sheng ZH, Baker C, Kobayashi H, Catterall WA (1996) Inhibition of neurotransmission by peptides containing the synaptic protein interaction site of N-type $\mathrm{Ca}^{2+}$ channels. Neuron 17:781-788.

Pan ZH, Segal MM, Lipton SA (1996) Nitric oxide-related species inhibit evoked neurotransmission but enhance spontaneous miniature synaptic currents in central neuronal cultures. Proc Natl Acad Sci USA 93:15423-15428.

Parfitt KD, Madison DV (1993) Phorbol esters enhance synaptic transmission by a presynaptic, calcium-dependent mechanism in rat hippocampus. J Physiol (Lond) 471:245-268.

Pascual O, Morin-Surun MP, Barna B, Denavit-Saubie M, Pequignot JM, Champagnat J (2002) Progesterone reverses the neuronal responses to hypoxia in rat nucleus tractus solitarius in vitro. J Physiol (Lond) 544:511-520.

Peng YJ, Overholt JL, Kline D, Kumar GK, Prabhakar NR (2003) Induction of sensory long-term facilitation in the carotid body by intermittent hypoxia: implications for recurrent apneas. Proc Natl Acad Sci USA 100:10073-10078.

Pinco M, Lev-Tov A (1993) Modulation of monosynaptic excitation in the neonatal rat spinal cord. J Neurophysiol 70:1151-1158.

Poncer JC, Esteban JA, Malinow R (2002) Multiple mechanisms for the potentiation of AMPA receptor-mediated transmission by alpha- $\mathrm{Ca}^{2+}$ / calmodulin-dependent protein kinase II. J Neurosci 22:4406-4411.

Poon CS, Siniaia MS (2000) Plasticity of cardiorespiratory neural processing: classification and computational functions. Respir Physiol 122:83-109. 
Popoli M (1993) Synaptotagmin is endogenously phosphorylated by $\mathrm{Ca}^{2+} /$ calmodulin protein kinase II in synaptic vesicles. FEBS Lett 317:85-88.

Powell FL, Huey KA, Dwinell MR (2000) Central nervous system mechanisms of ventilatory acclimatization to hypoxia. Respir Physiol 121:223-236.

Prabhakar NR, Kline DD (2002) Ventilatory changes during intermittent hypoxia: importance of pattern and duration. High Alt Med Biol 3:195-204.

Rettig J, Heinemann C, Ashery U, Sheng ZH, Yokoyama CT, Catterall WA, Neher E (1997) Alteration of $\mathrm{Ca}^{2+}$ dependence of neurotransmitter release by disruption of $\mathrm{Ca}^{2+}$ channel/syntaxin interaction. J Neurosci 17:6647-6656.

Sara Y, Virmani T, Deak F, Liu X, Kavalali ET (2005) An isolated pool of vesicles recycles at rest and drives spontaneous neurotransmission. Neuron 45:563-573.

Schild JH, Clark JW, Canavier CC, Kunze DL, Andresen MC (1995) Afferent synaptic drive of rat medial nucleus tractus solitarius neurons: dynamic simulation of graded vesicular mobilization, release, and nonNMDA receptor kinetics. J Neurophysiol 74:1529-1548.

Schmitt P, Soulier V, Pequignot JM, Pujol JF, Denavit-Saubie M (1994) Ventilatory acclimatization to chronic hypoxia: relationship to noradrenaline metabolism in the rat solitary complex. J Physiol (Lond) 477:331-337.

Schoch S, Deak F, Konigstorfer A, Mozhayeva M, Sara Y, Sudhof TC, Kavalali ET (2001) SNARE function analyzed in synaptobrevin/VAMP knockout mice. Science 294:1117-1122.

Selig DK, Hjelmstad GO, Herron C, Nicoll RA, Malenka RC (1995) Independent mechanisms for long-term depression of AMPA and NMDA responses. Neuron 15:417-426.
Stanton PK, Gage AT (1996) Distinct synaptic loci of $\mathrm{Ca}^{2+} /$ calmodulindependent protein kinase II necessary for long-term potentiation and depression. J Neurophysiol 76:2097-2101.

Sudhof TC (1995) The synaptic vesicle cycle: a cascade of protein-protein interactions. Nature 375:645-653.

Trussell LO, Zhang S, Raman IM (1993) Desensitization of AMPA receptors upon multiquantal neurotransmitter release. Neuron 10:1185-1196.

Turrigiano GG, Nelson SB (2004) Homeostatic plasticity in the developing nervous system. Nat Rev Neurosci 5:97-107.

Vidruk EH, Olson Jr EB, Ling L, Mitchell GS (2001) Responses of singleunit carotid body chemoreceptors in adult rats. J Physiol (Lond) 531:165-170.

Washbourne P, Thompson PM, Carta M, Costa ET, Mathews JR, LopezBendito G, Molnar Z, Becher MW, Valenzuela CF, Partridge LD, Wilson MC (2002) Genetic ablation of the t-SNARE SNAP-25 distinguishes mechanisms of neuroexocytosis. Nat Neurosci 5:19-26.

Welsby PJ, Wang H, Wolfe JT, Colbran RJ, Johnson ML, Barrett PQ (2003) A mechanism for the direct regulation of T-type calcium channels by $\mathrm{Ca}^{2+} /$ calmodulin-dependent kinase II. J Neurosci 23:10116-10121.

Yokoyama CT, Sheng ZH, Catterall WA (1997) Phosphorylation of the synaptic protein interaction site on N-type calcium channels inhibits interactions with SNARE proteins. J Neurosci 17:6929-6938.

Zengel JE, Sosa MA (1994) Changes in MEPP frequency during depression of evoked release at the frog neuromuscular junction. J Physiol (Lond) 477:267-277.

Zucker RS, Regehr WG (2002) Short-term synaptic plasticity. Annu Rev Physiol 64:355-405. 